\title{
Usage of Biomass-based Carbon Materials as Lubricant Additive: Effects on Rheological and Tribological
}

\section{Properties}

\author{
Adewale George Adeniyi 1,*(i), Sulyman Age Abdulkareem 1, Joshua O. Ighalo ${ }^{1,2}{ }^{\mathbb{D}}$, Mutiu K. Amosa ${ }^{3}$, \\ Ayobami O. Popoola ${ }^{1}$, Samuel Ogunniyi ${ }^{1}{ }^{\mathbb{D}}$, Maryam T. Abdulkareem ${ }^{1}$ \\ 1 Department of Chemical Engineering, Faculty of Engineering and Technology, University of Ilorin, Ilorin, P. M. B. 1515, \\ Nigeria \\ 2 Department of Chemical Engineering, Nnamdi Azikiwe University, P. M. B. 5025, Awka, Nigeria \\ 3 National Improved Oil Recovery Centre, Department of Petroleum Resources, Victoria Island, Lagos, Nigeria \\ * Correspondence: adeniyi.ag@unilorin.edu.ng;
}

Scopus Author ID 57203847713

Received: 23.02.2021; Revised: 5.04.2021; Accepted: 8.04.2021; Published: 9.05.2021

\begin{abstract}
Lubricating oils are thick and sticky fluids used for greasing moving parts of machines and engines. This paper expresses key advances in surface engineering and the use of biomass materials as lubricant additives. In order to enhance the lubrication characteristics of base oil, the biochar lubricant additives were successfully prepared. The tribological behaviors of biochar (biomass and hybrid) lubricant additives in two types of base oils (SN500 and SN900) were evaluated. In the current study, biomass-based carbon materials (biochar and hybrid) from a thermochemical conversion unit were employed as a lubricant additive. The rheological and tribological behavior of the base oil modified with biochar additives were experimentally determined. Surface analyses via SEM confirmed the surface enhancement of the worn exterior plane via the effect produced by the biochar additives. It was also observed that the biomass biochar using SN900 improved the kinematic viscosities of the base oil more than the hybrid biochar. This may be attributed to the chars' fundamental composition, which makes the fluid's internal resistance flow under gravitational force. With SN500, the viscosity index improves with the biochar from 106 to108 but is reduced for SN900 from 102 to 97.09.
\end{abstract}

Keywords: biochar; lubricant; viscosity.

(C) 2021 by the authors. This article is an open-access article distributed under the terms and conditions of the Creative Commons Attribution (CC BY) license (https://creativecommons.org/licenses/by/4.0/).

\section{Introduction}

Boundary lubricants (BL) are essentially needed in mechanical systems as long as surface contact and motion are involved [1]. They are made of base oil and additives in average percentage composition of 93 and 7, respectively. BL formulations are diverse in types and applications. The choice and percentage of additive largely depend on the expected application areas, which in turn determines the cost of production [2]. In recent times, different carbonbased particles were used in lubricant oils formulation as additives to advance the lubrication properties of the common lubricants [3-6]. Load carrying capacity improvement, viscosity stability with cycles of use, reducing frictional phenomena, and decreasing wear are evidence of mechanical system reliability once the additive choice is compatible in lubricant oil formulation [7-9]. 
From biomass and non-biomass sources, carbon-based materials have been adjudged as environmentally compatible lubricating materials [10]. Wei, Cai, Zhou, and Liu [10] prepared an onion-like carbon raw material was from candle soot and investigated its tribological properties. This additive was found to effectively reduce both the friction and wear of the tested sliding pairs. The significant upshoot of diesel soot on lubricant oil viscosity was also investigated by George, Balla, and Gautam [11]. The thickness of the tested oil samples increased with an increase in soot at the temperature vary between 40 and $90^{\circ} \mathrm{C}$. This temperature range is suitable for a vast range of common mechanical systems. Exhaust diesel soot [12], graphene nano-sheets, carbon nanotubes, graphene oxides, etc. [13] had previously found excellent application as a lubricant additive and had a positive effect on tribological properties of lubricants. In the broader evaluation, soot and other synthesized carbon material are excellent carbon materials for lubricant viscosity improver.

In this present study, biomass-based carbon materials (biochar and soot) from a thermochemical conversion unit are employed as a lubricant additive. The biochar and soot, as previously obtained for many biomass [14-19], were obtained from the thermochemical conversion of elephant grass (Pennisetum purpureum) [15] in this work. Details of the production process are given elsewhere [16, 20-22]. This thermochemical facility, powered by updraft gasification of biomass, has been optimized for biochar production with deposited soot as a by-product [18]. Within the scope of the authors' exhaustive search, the biochar produced from elephant grass (Pennisetum purpureum) has not been applied as a lubricant additive. This, therefore, underlines the novelty of the current study.

\section{Materials and Methods}

\subsection{Biochar production.}

The biochar utilized in this study was produced according to the methods described in Adeniyi, Ighalo, and Onifade [20] and Adeniyi, Ighalo, and Onifade [21]. Two types of biochar are produced for the study: hybrid biochar and single biochar. The biomass biochar was produced solely from elephant grass (Pennisetum purpureum), while the hybrid biochar was produced from a feed ratio of 35:1 biomass to LDPE. The disparity is not that great in terms of volume due to the plastic's very low effective density. The yield of hybrid biochar and biomass biochar was $27.3 \mathrm{wt} \%$ (at $382^{\circ} \mathrm{C}$ peak temperature) and $13.8 \mathrm{wt} \%$ (at $371^{\circ} \mathrm{C}$ peak temperature).

\subsection{Biochar characterization.}

The surface morphology and approximate constituents of the biomass biochar and hybrid biochar were determined using Scanning Electron Microscope with Energy Dispersive X-ray Spectroscopy (SEM-EDS). Scanning Electron Microscopy (SEM, Phenom proX, Phenom-World BV, Netherlands) was conducted at an acceleration voltage of $15 \mathrm{kV}$ and magnification of $1500 \times$.

\subsection{Application as lubricant additive.}

Base oil was heated to $60^{\circ} \mathrm{C}$ on the electric heater to evaporate the moisture content to produce the hot base oil. The produced biochar $(2 \%)$ and hot base oil $(98 \%)$ were weighed for each mixing. The mixtures were subjected to continuous random mixing to ease the miscibility of char in the hot base oil until a homogenous mixture was achieved. 


\subsection{Viscosity test for rheological and tribological properties.}

The rheological characterization experiment of the lubricant additive was conducted using a conventional viscometer with a temperature bath. The equipment has varying speed capability of $0.01-200 \mathrm{rpm}$, a testing temperature varying between $0^{\circ} \mathrm{C}$ to $100^{\circ} \mathrm{C}$, and a maximum shear rate of $57 \mathrm{~s}^{-1}$ at $195 \mathrm{rpm}$. The viscosity changes at $40^{\circ} \mathrm{C}\left(\mathrm{V}_{40}\right)$ and $100^{\circ} \mathrm{C}\left(\mathrm{V}_{100}\right)$ were taken to ascertain the Newtonian or non-Newtonian behavior of the lubricants studied.

\section{Results and Discussion}

\subsection{Biochar characterization.}

\subsection{1. composition.}

The major rudimentary constitution of the biomass biochar and hybrid biochar obtained from the EDS analysis is summarised in Figure 1. The spectrums for the biomass biochar and hybrid biochar are expressed in Figures $2 \mathrm{a}$ and $2 \mathrm{~b}$, respectively. It can be observed that the major constituent of both biochars is carbon. However, the hybrid biochar had a significantly higher carbon content than the biomass biochar. This is likely due to the effect of plastic doping on the feedstock. Plastics have a higher carbon content than biomass (per $\mathrm{kg}$ ) and invariably lead to a carbon-rich char.

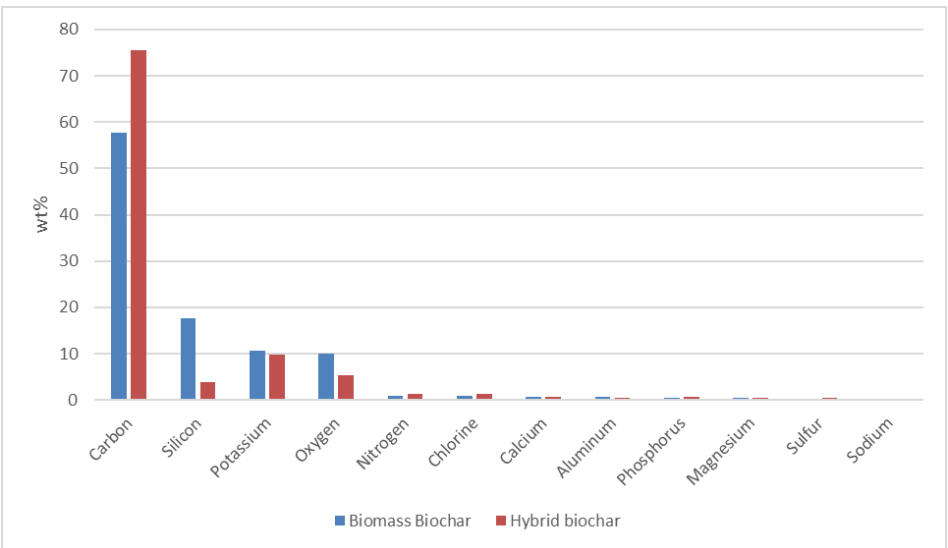

Figure 1. Elemental composition obtained for the biomass and hybrid biochar.

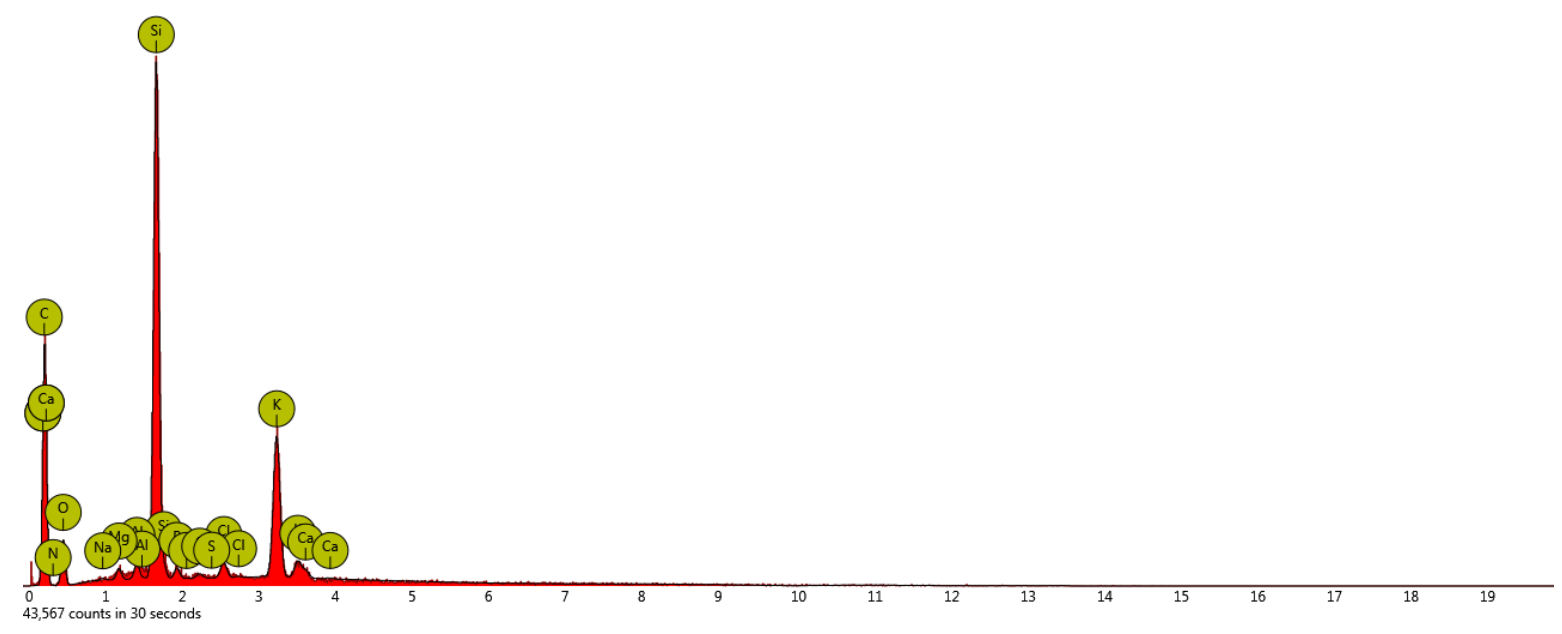

Figure 2a. EDS spectrum for biomass biochar.

Minerals like silicon, potassium, calcium, and aluminum are marginally higher in biomass biochar. This higher mineral content will likely be of advantage in improving the 
calorific value of the lubrication oil. The only constituent of the biomass not included in this analysis is hydrogen. This is because Electron Dispersive Spectroscopy (EDS) is a test to examine the presence of elements through the amplitude of wavelength for the $\mathrm{x}$-ray emitted after the electron beam hits the electron. For the emission of $\mathrm{x}$-ray, the atoms must contain a minimum of K-shell and L-shell where the electron is allowed to dislodge from shell to shell. Therefore, hydrogen is the only element present in the periodic table with only $\mathrm{K}$ shell, is not detectable with EDS [23, 24]. The higher oxygen content in the biomass biochar is due to the nature of the biomass itself.

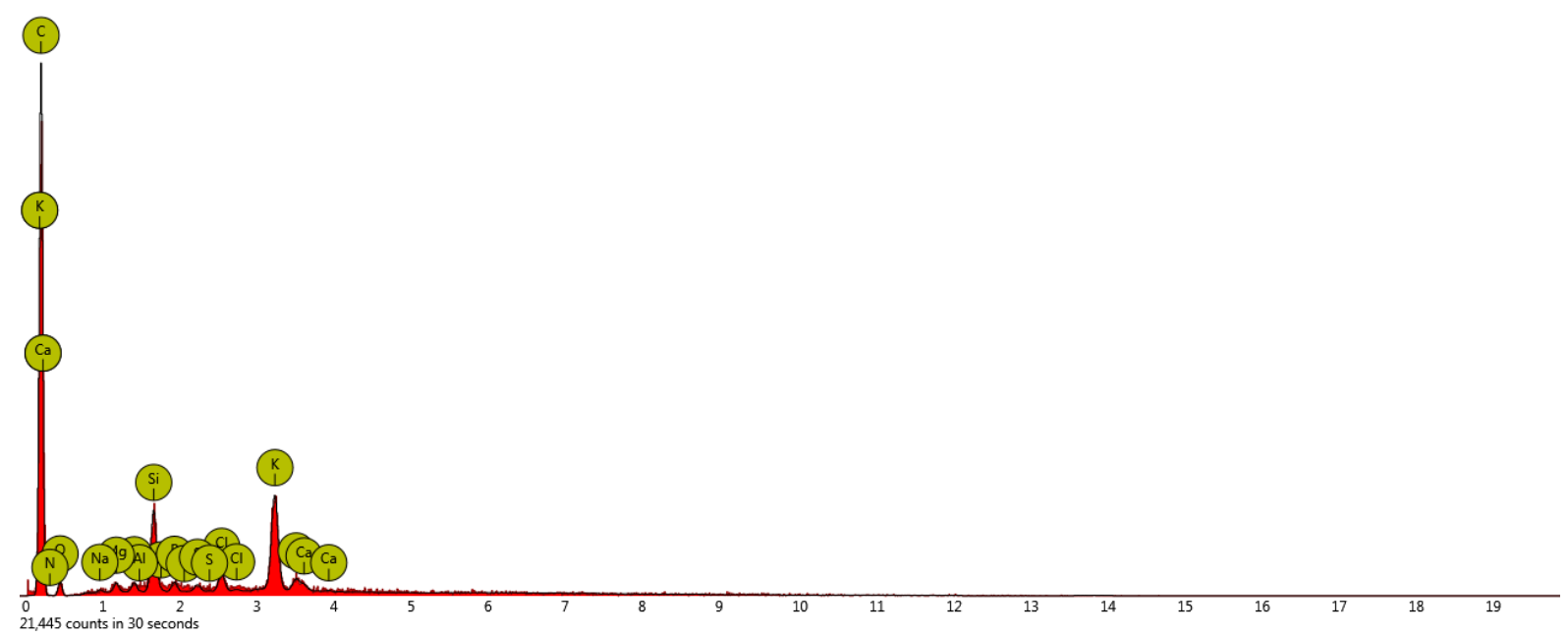

Figure 2b. EDS spectrum for hybrid biochar.

\subsubsection{Surface morphology.}

The surface morphology of the biomass biochar and hybrid biochar is shown in Figures $3 \mathrm{a}$ and $3 \mathrm{~b}$, respectively. The biomass biochar had a smooth and continuous surface with some minor cracks and voids. The hybrid biochar had a smooth surface with observable hexagonal formations. Both biochars had heterogeneous structures, with the hybrid char being noticeably more porous. The white spots on the hybrid biochar surfaces are perhaps oxides of potassium and silicon, as these are the other main elements besides carbon (from the EDS).

\subsection{Improvement of rheological and tribological properties on viscosity.}

Table 1 and 2 show chars' viscosity produced as lubricant additives on different base oils (SN500 and SN900). There were substantial improvements in the viscometric results when the chars were blended with the base oils. The viscosity of the produced lubricant was determined to know its strength to decrease friction in solid body interactions. The viscosity index was used to describe the viscosity-temperature comportment of the lubricating oil. It is an arbitrary, unitless measure of variation in viscosity in relation to temperature change [25]. With SN500, biochar improves the viscosity index from 106 to108, making it more stable but reduced SN900 from 102 to 97.09 . The lesser the VI, the more the viscosity is influenced by variations in temperature. The greater the VI, the steadier the viscosity relics over temperature changes. Hybrid biochar, on the other hand, reduced the viscosity index of SN500 and SN900.

The kinematics viscosity was determined by taking notice of the time it takes the base oil to circumnavigate the orifice of the capillary under the influence of gravity. From Table 2, it was observed that SN900 tends to have higher kinematics viscosity values which make the fluid's internal resistance to flow under gravitational force. From the test conducted, SN900 
provides better test repeatability or consistency than the SN500. It was also observed that the biomass biochar improved the kinematic viscosities of the base oil more than the hybrid biochar. This may be attributed to the chars' fundamental composition; Biochar and hybrid char have $17.55 \%$ and $3.95 \%$ silicon, respectively.

Finally, for SN500, the kinematics viscosity steadies out for all forms of char additives contrary to SN900. The viscosity is greater in SN900 base oil, and it experiences shear thinning behavior until the end. Viscosity is dependent on the concentration of the char in the base oil. As the concentration of biochar increases, the viscosity decrease. Therefore, concluding that the lubricant's viscosity behavior depends on the amount of biochar present [26].

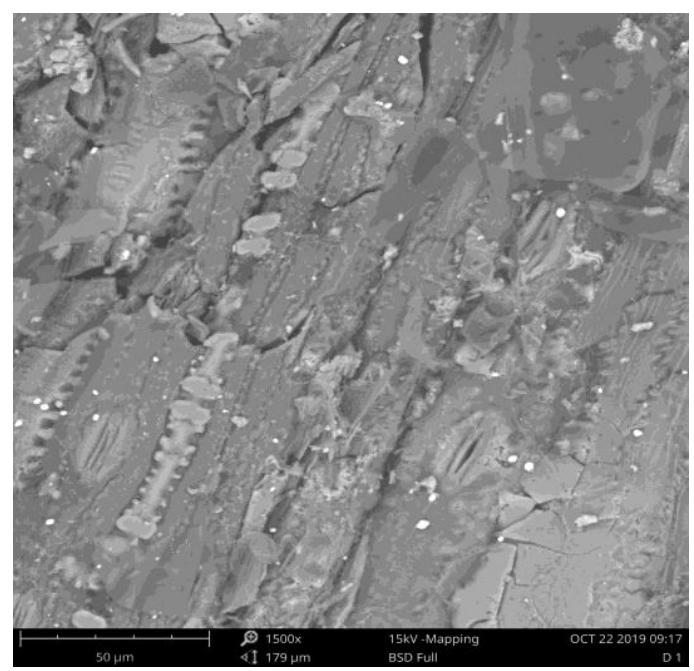

(a)

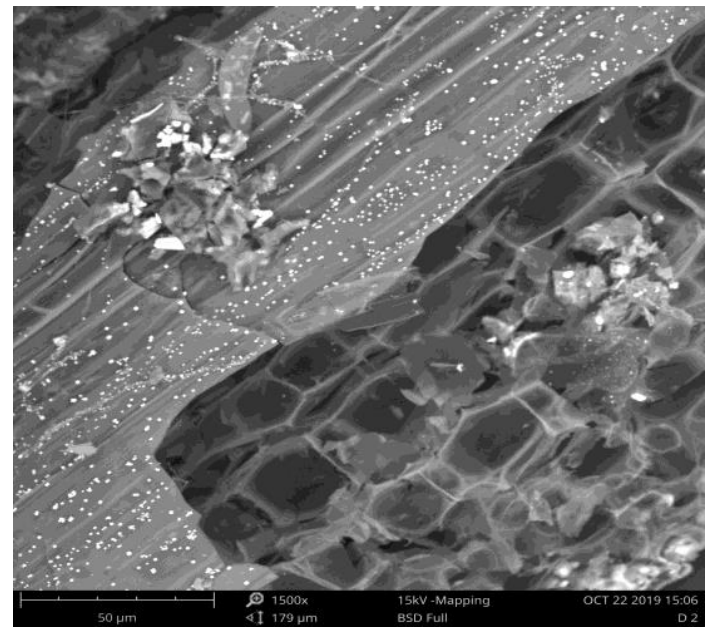

(b)

Figure 3. SEM micrograph of biomass biochar (a) and hybrid biochar (b) at a magnification of 1500x

Table 1. Kinematic viscosity and viscosity index (VI) of SN500 base oil.

\begin{tabular}{l|c|c|c} 
Char & $\mathbf{V}_{\mathbf{4 0}} \mathbf{c S t}\left(\mathbf{m m}^{2} / \mathbf{s}\right)$ & $\mathbf{V}_{\mathbf{1 0 0}} \mathbf{c S t}\left(\mathbf{m m}^{\mathbf{2}} \mathbf{s}\right)$ & VI \\
\hline Nil & 95.92 & 11.35 & 106 \\
\hline Biochar & 110.44 & 12.72 & 108 \\
\hline Hybrid Biochar & 108.70 & 12.13 & 101.29
\end{tabular}

Table 2. Kinematic viscosity and viscosity index (VI) of SN900 base oil.

\begin{tabular}{l|c|c|c} 
Char & $\mathbf{V}_{\mathbf{4 0}} \mathbf{~} \mathbf{S t}\left(\mathbf{m m}^{\mathbf{2}} / \mathbf{s}\right)$ & $\mathbf{V}_{\mathbf{1 0 0}} \mathbf{c S t}\left(\mathbf{m m}^{\mathbf{2}} \mathbf{s}\right)$ & $\mathbf{V I}$ \\
\hline Nil & 159.29 & 15.81 & 102 \\
\hline Biochar & 178.58 & 16.57 & 97.09 \\
\hline Hybrid Biochar & 177.38 & 16.76 & 99.45
\end{tabular}




\subsection{Analysis of the anti-friction/wear mechanisms.}

The friction coefficient of SN900 was higher than that of SN500. This can be ascribed to the removal of polar components such as organic oxides and organic nitrides with lubrication properties during desulfurization, which lessens the lubricating properties of low-sulfur fuel. The ultra-thin sheet structure and the smooth surface of biochar make it easy to fill in the valleys between two asperities. However, when the biochar in the base oil (SN500 and SN900) reached a certain concentration, the biochar additives that entered the contact surface were saturated. As the concentration of biochar further increases, biochar agglomerates, resulting in increased friction.

The small structure of biochar additives easily enters friction pairs' contact plane to form a layer of anti-friction protective film. The protective film effectively stops direct contact between two asperities and significantly lessens friction. Biomass carbon possesses extremely low shear stress, thin structure, and high load-carrying capacity [25]. These ensure that biochar can easily move into the rubbing surfaces and form a low-shear, high durability oil film to hinder direct surface to surface contacts, which leads to the reduction of friction and wear. Therefore, biochar additives effectively improve the lubrication performance of the base oil (SN500 and SN900).

\section{Conclusions}

In this study, a simple, cost-effective, and pollution-free method was established to prepare biochar lubricant additives using two different base oils. The base oil without any other chemical components was conducted as a modifier. The base oil's tribological and rheological dynamics with no biochar, hybrid, and biomass biochar lubricant additives were investigated. The preparation and surface modification of biochar lubricant additives were completed. Biochar lubricant additives had good compatibility with SN900 base oil. During the experiment, reactions such as ionization, gasification, or cracking of molecular bonds took place with low sulfur fuel, and many organic functional groups were generated based on the EDS result. These organic functional groups were polymerized or adsorbed onto the surface of the biochar, and the long-chain hydrocarbon structure akin to that of the base oil was formed on the apparent layer of the biochar. Biochar lubricant additives greatly enhanced the lubrication performance of the base oil. Surface analyses via SEM established the surface enhancement of the dilapidated surfaces through the polishing effect produced by the biochar additives.

It is well understood that the biomass's chemical constituents have an exact impact on the physical quality of the biochar produced and that thermal decomposition of the carbonbased material changes with temperature. As the temperature increases, the cellular water vaporizes; the organics experience thermo-chemical decomposition, and finally, the mineral content materializes as ash that, sequentially, can sinter under greater temperatures. The production of biochar from biomass used as additives for lubrication oil helps to reduce environmental concern which it has so far posed. It will also decrease the demand for lubricantrich crude, which is a limited resource.

The reduced friction coefficient and high wear resistance may form an amorphous carbon film transferred from the biomass biochar. The dark-colored nature of the surfaces validates this hypothesis, but further investigations on the chemistry of the dilapidated surfaces are required to divulge the real mechanisms of improving the system's tribological behaviors. 


\title{
Funding
}

This research received no external funding.

\section{Acknowledgments}

\begin{abstract}
The support of Lubcon Nigeria Limited is appreciated. Their Rheological facilities were made available for the related analysis.
\end{abstract}

\section{Conflicts of Interest}

The authors declare no conflict of interest.

\section{References}

1. Zulkifli, N.W.M.; Kalam, M.A.; Masjuki, H.H.; Yunus, R. Experimental Analysis of Tribological Properties of Biolubricant with Nanoparticle Additive. Proc. Eng. 2013, 68, 152-157, https://doi.org/10.1016/j.proeng.2013.12.161.

2. Fan, X.; Xue, Q.; Wang, L. Carbon-based solid-liquid lubricating coatings for space applications-A review. Friction 2015, 3, 191-207, https://doi.org/10.1007/s40544-015-0079-1.

3. Golan, Y.; Drummond, C.; Homyonfer, M.; Feldman, Y.; Tenne, R.; Israelachvili, J. Microtribology and Direct Force Measurement of WS2 Nested Fullerene-Like Nanostructures. Adv. Mat. 1999, 11, 934-937, https://doi.org/10.1002/(SICI)1521-4095(199908)11:11\%3C934::AID-ADMA934\%3E3.0.CO;2-L.

4. Golan, Y.; Drummond, C.; Israelachvili, J.; Tenne, R. In situ imaging of shearing contacts in the surface forces apparatus. Wear 2000, 245, 190-195, https://doi.org/10.1016/S0043-1648(00)00478-6.

5. Gupta, B.K.; Bhushan, B.J.L.E. Fullerence particles as an additive to liquid lubricants and greases for low friction and wear. Lub. Eng. 1994, 50, 524-528.

6. Hu, E.; Hu, X.; Liu, T.; Liu, Y.; Song, R.; Chen, Y. Investigation of morphology, structure and composition of biomass-oil soot particles. App. Sur. Sci. 2013, 270, 596-603, https://doi.org/10.1016/j.apsusc.2013.01.091.

7. Hunter, C.N.; Check, M.H.; Hager, C.H.; Voevodin, A.A. Tribological Properties of Carbon Nanopearls Synthesized by Nickel-Catalyzed Chemical Vapor Deposition. Trib. Lett. 2008, 30, 169-176, https://doi.org/10.1007/s11249-008-9324-3.

8. Matsumoto, N.; Joly-Pottuz, L.; Kinoshita, H.; Ohmae, N. Application of onion-like carbon to micro and nanotribology. Diam. Rel. Mat. 2007, 16, 1227-1230, https://doi.org/10.1016/j.diamond.2007.01.031.

9. Adeniyi, A.; Adewoye, T.; O. Ighalo, J. Computer Aided Simulation of the Pyrolysis of Waste Lubricating Oil Using Aspen Hysys. Env. Res., Eng. Man. 2018, 74, 52-57, https://doi.org/10.5755/j01.erem.74.2.20537.

10. Wei, J.; Cai, M.; Zhou, F.; Liu, W. Candle Soot as Particular Lubricant Additives. Trib. Lett. 2014, 53, 521531, https://doi.org/10.1007/s11249-013-0290-z.

11. George, S.; Balla, S.; Gautam, M. Effect of diesel soot contaminated oil on engine wear. Wear 2007, 262, 1113-1122, https://doi.org/10.1016/j.wear.2006.11.002.

12. Zhang, Z.-C.; Cai, Z.-B.; Peng, J.-F.; Zhu, M.-H. Comparison of the tribology performance of nano-diesel soot and graphite particles as lubricant additives. J. Phy. D: App. Phy. 2015, 49, https://doi.org/10.1088/0022-3727/49/4/045304.

13. Kiu, S.S.K.; Yusup, S.; Chok, V.S.; Taufiq, A.; Kamil, R.N.M.; Syahrullail, S.; Chin, B.L.F. Comparison on tribological properties of vegetable oil upon addition of carbon based nanoparticles. IOP Conf. Series: Mat. Sci. Eng. 2017, 206, https://doi.org/10.1088/1757-899X/206/1/012043.

14. Adelodun, A.A.; Adeniyi, A.G.; Ighalo, J.O.; Onifade, D.V.; Arowoyele, L.T. Thermochemical conversion of oil palm Fiber-LDPE hybrid waste into biochar. Biof., Biop. Bior. 2020, 14, 1313-1323, https://doi.org/10.1002/bbb.2130.

15. Adeniyi, A.; O. Ighalo, J.; Onifade, D.; Popoola, A. Production of Hybrid Biochar by Retort-Heating of Elephant Grass (Pennisetum Purpureum) and Low Density Polyethylene (LDPE) for Waste Management and Product Development. J.Mat. Env. Sci. 2020, 11, 1940-1952.

16. Adeniyi, A.G.; Abdulkareem, S.A.; Ighalo, J.O.; Onifade, D.V.; Sanusi, S.K. Thermochemical Coconversion of Sugarcane Bagasse-LDPE Hybrid Waste into Biochar. Arab. J. Sci. Eng. 2020, https://doi.org/10.1007/s13369-020-05119-9.

17. Adeniyi, A.G.; Ighalo, J.O.; Onifade, D.V. Production of biochar from elephant grass (Pernisetum purpureum) using an updraft biomass gasifier with retort heating. Biofuels 2019, 1-8, https://doi.org/10.1080/17597269.2019.1613751. 
18. Adeniyi, A.G.; Ighalo, J.O.; Onifade, D.V. Biochar from the Thermochemical Conversion of Orange (Citrus sinensis) Peel and Albedo: Product Quality and Potential Applications. Chem. Africa 2020, 3, 439-448, https://doi.org/10.1007/s42250-020-00119-6.

19. Ighalo, J.O.; Onifade, D.V.; Adeniyi, A.G. Retort-heating carbonisation of almond (Terminalia catappa) leaves and LDPE waste for biochar production: evaluation of product quality. Int. J.Sus. Eng. 2021, https://doi.org/10.1080/19397038.2021.1886371.

20. Adeniyi, A.G.; Ighalo, J.O;; Onifade, D.V. Production of Bio-Char from Plantain (musa Paradisiaca) Fibers Using an Updraft Biomass Gasifier with Retort Heating. Comb. Sci. Tech. 2021, 193, 60-74, https://doi.org/10.1080/00102202.2019.1650269.

21. Adeniyi, A.G.; Abdulkareem, S.A.; Ighalo, J.O.; Onifade, D.V.; Adeoye, S.A.; Sampson, A.E. Morphological and thermal properties of polystyrene composite reinforced with biochar from elephant grass (Pennisetum purpureum). J. Ther. Comp. Mat. 2020, https://doi.org/10.1177\%2F0892705720939169.

22. Swapp, S. Scanning Electron Microscopy (SEM). Geochemical instrumentation and analysis 2012

23. Goldstein, J. Scanning electron microscopy and $x$-ray microanalysis. Kluwer Adacemic: Plenum Pulbishers, 2003.

24. Cornelio, J.A.C.; Cuervo, P.A.; Hoyos-Palacio, L.M.; Lara-Romero, J.; Toro, A. Tribological properties of carbon nanotubes as lubricant additive in oil and water for a wheel-rail system. J. Mat.Res. Tech. 2016, 5, 68-76, https://doi.org/10.1016/j.jmrt.2015.10.006.

25. Hou, X.; Ma, Y.; Bhandari, G.; Yin, Z.; Dai, L.; Liao, H.; Wei, Y. Preparation and Tribological Properties of Graphene Lubricant Additives for Low-Sulfur Fuel by Dielectric Barrier Discharge Plasma-Assisted Ball Milling. Processes 2021, 9, https://doi.org/10.3390/pr9020272. 